\title{
NOTE ON RETINO-CHOROIDAL RUPTURES
}

\author{
BY \\ J. Herbert Parsons, \\ LONDON.
}

RUPTURES of the choroid are common as result of injuries to the eye; but in the ordinary accidents of civil life the overlying retina is only rarely torn. Ruptures of both choroid and retina are very frequently found in war injuries of the eye. Attention has been specially drawn to this fact by Professor Lagrange in his recently published book on "Fractures of the Orbit."* When the choroid alone is ruptured, a scar composed of a quite limited amount of fibrous tissue is formed. Unless the immediate vicinity of the macula is involved, there is relatively little impairment of vision. When, however, both choroid and retina are ruptured, very considerable masses of fibrous tissue are formed, often projecting into the vitreous, and throwing out processes which resemble those of retinitis proliferans. These masses are very characteristic, and are admirably illustrated in Professor Lagrange's book. It is of interest to search for a possible explanation of their formation.

Some years ago, in a paper on the healing of wounds of the retina, choroid and sclera, $t$ I ventured to suggest an explanation of some of the peculiarities of retinitis proliferans. The following is a quotation from that paper: "Some toxic condition leads to a retinal hæmorrhage. If it is situated in the peripheral parts of the retina, or is due to rupture of the smaller vessels nearer the papilla-in other words, if it is a small hæmorrhage-no large proliferation of new tissue will result. A scar will result from the organization of the clot through the medium of the scanty mesoblastic tissue of the walls of the smaller retinal vessels. If, however, a large hæmorrhage occurs, it will be in the neighbourhood of the disc, or if caused by repeated hæmorrhages in slightly more peripheral parts, will yet invade the neighbourhood of the larger vessels, i.e., again the neighbourhood of the disc. Now, it is around the larger vessels, and par excellence upon the disc, that the main mass of retinal mesoblastic tissue is situated. At the papilla itself, we have not only the walls of the vessels, but also remnants of the hyaloid artery and a ring of anastomoses with posterior ciliary vessels - in fact, the largest mass of mesoblastic tissue found in the walls of the true optic cup. The nearer the hæmorrhage approaches this point, and the more widespread its traumatic and irritating effects in this immediate

* Reviewed on page 524 of this Journal.

† Parsons : Royal Lond. Ophthal. Hosp. Rep., Vol. XV, p. 251, 1903. 
neighbourhood, the more tissue will be excited to reparative reaction, and the greater will be the proliferation and organization. Hence the fact that retinitis proliferans invariably springs from the disc or its vicinity. In the periphery there are two factors acting against such proliferation: first, the smallness of the hæmorrhage, which, however, may possibly be increased by repetition or multiplicity and confluence; second, and more important, the small amount of tissue which is capable of proliferating and inducing organization."

The proliferation of fibrous tissue in the scars of retino-choroidal ruptures would appear to be susceptible of a similar explanation. In these cases there is a considerable extravasation of blood from the choroid and retina into the vitreous, which is torn up, and, as it were, fractured by the rush of blood. In the ordinary vitreous hæmorrhage, due to rupture of retinal vessels, there is little mesoblastic tissue in contact with the blood capable of providing fibroblasts to bring about organization of the clot. The vitreous itself is inert, and its scanty cells appear to have little organizing capacity. Hence the blood is absorbed and only in exceptional cases does so-called "retinitis proliferans" occur. When both choroid and retina are ruptured the mesoblastic choroid affords an ample supply of active fibroblasts, and the clot organizes into a mass of fibrous tissue in exactly the same manner as in a hæmorrhage into the other connective tissues.

If this suggestion is correct, it provides an argument against the method of removing foreign bodies from the vitreous by introducing the pole of the small magnet through an incision which perforates sclerotic, choroid and retina. By this method the choroidal fibroblasts are enabled to escape into the track of the wound and lead to exuberant fibrous tissue formation. By the alternative method of drawing the foreign body into the anterior chamber with the giant magnet, preparatory to its removal from the eye, the track is not put into relationship with any considerable mass of potential fibroblasts, and consequently little fibrous tissue is likely to be formed. The risks of detachment of the retina, etc., from contraction of bands of scar tissue are thus minimized.

\section{ANNOTATIONS}

\section{Specialism and Special Hospitals}

IT is scarcely necessary in a journal devoted to a special branch of medicine to enumerate the arguments in favour of specialism in medicine. Yet conservative instincts are strong, and there are still 